\title{
Editorial
}

\section{Why do we do clinic and how on earth do we manage it?}

Elaine Hall

Northumbria University, UK

Elaine.Hall@northumbria.ac.uk

In this edition we continue the conversation linking values, intent, pedagogy and context to understand the complexity of clinic in the $21^{\text {st }}$ Century.

We begin with a paper from Martha Simmons and Marian Mac Gregor that challenges us to consider who can contribute to clinical work. Their focus on students with disabilities and the challenges and opportunities of providing access to clinic is timely and compelling. We are witnessing an expansion of clinical programmes which can be an opportunity to ask ourselves where the evidence lies that some students are better suited to clinic than others, whether there are pre-existing attributes that fit students to serve our communities or whether social justice ideals demand that more diverse students get to benefit form a clinical experience.

Following on from their paper on emotional competency in interviewing ${ }^{1}$ we have a new paper from Colin James and Felicity Wardhaugh exploring the emotional impact of clinical work and the pedagogies and experiences that can support students in

${ }^{1}$ IJCLE 20, 2, 2014 
providing both client-centred practice and the kind of self-care that enables long term professional resilience.

Ann Thanaraj's paper elaborates the theme of student development and identity, using a methodological framework unusual in legal studies. This phenomenographic approach offers the potential to capture data that has proved elusive in the past and others may find it helpful as a way of making more concrete their felt sense of what students gain from the clinic.

We are grounded in the realities of sustaining clinic by our Practice Report from Barbara Preložnjak and Juraj Brozović, who describe the Croatian context with great detail and energy. Readers will immediately make the link to the key themes for sustainability identified by Tribe $\mathrm{Mkwebu}^{2}$ and we welcome this paper and any others that colleagues might wish to share from their own countries.

We end this edition (as T.S. Eliot predicted) at the beginning, with the voices of law students, by showcasing the winners of the 2016 Pro Bono Essay competition at Northumbria University. They sum up the various approaches to understanding clinical work: academic, idealistic, pragmatic and above all highly personal. We all have our motivations and our rewards, one model does not have to 'win' in order for clinic to flourish.

\footnotetext{
${ }^{2}$ Mkwebu, T. (2015) A Systematic Review of Literature on Clinical Legal Education: A Tool for Researchers in Responding to an Explosion of Clinical Scholarship IJCLE, 22, 3 Mkwebu, T. (2016) Unpacking Clinical Scholarship: Why Clinics Start and How They Last, AJLE $(3,3)$ forthcoming, available online
} 
As you will hopefully have heard through your networks, three organisations are coming together for the 2017 conference. We look forward to welcoming you to Newcastle!

\section{IJCLE - ENCLE - CLEO}

The International Journal of Clinical Legal Education in association with the

European Network for Clinical Legal Education

and the

United Kingdom Clinical Legal Education Organisation

\section{CONFERENCE 3-5 JULY 2017}

at the University of Northumbria, Newcastle upon Tyne, UK

"Bringing It All Together: Clinical Legal Educators in the 21st Century University"

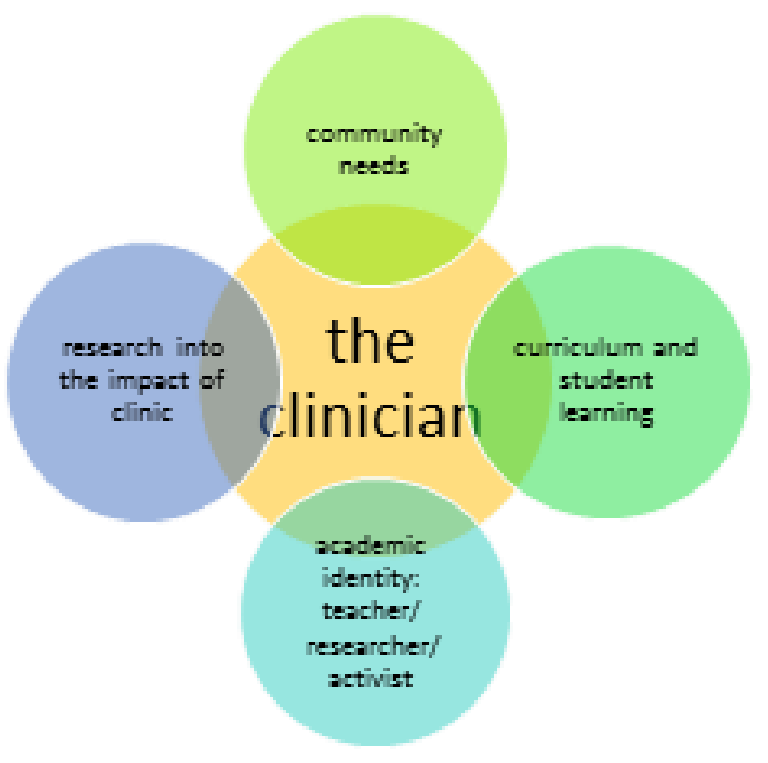


Clinicians wear many hats: teacher, group facilitator, project manager, lawyer, researcher, mentor, activist, administrator, supervisor, academic, fund raiser, practice manager, collaborator, role model, counsellor...

This year's conference continues our exploration of the key, often overlapping, issues arising for clinical legal education in the $21^{\text {st }}$ century from the clinician's perspective; juggling sometimes competing priorities and often making difficult choices. Papers are invited which consider one or more of these themes below while still encouraging participants to locate their papers either mainly in one of those areas or by exploring the overlaps.

Themes:

- The clinician and community needs

- The clinician and research into the impact of clinic

- The clinician and academic identity

- The clinician and curriculum and student learning

In particular, we would like to encourage participants to include student and other partners' voices in their presentations, ideally through collaborative writing and presentation in person or through video calling or recordings.

\section{Taking part}

Presentations at IJCLE/ENCLE/CLEO can take one of three formats, each with its own structured proposal application form: 
- Paper presentation

- These will be in traditional conference paper format, with a twenty minute presentation followed by questions. Participants will be invited to indicate if their paper falls into one or more of the four areas: Community Need; Curriculum and Students; Academic Identity; Research and Impact.

- Interactive seminar

- These sessions will be 90 minutes long, will involve active participation from the audience as well as input from the presenters and will be designed to generate discussion and new learning for the participants and the convenors. Participants will be invited to indicate if their seminar falls into one or more of the four areas: Community Need; Curriculum and Students; Academic Identity; Research and Impact.

- PechaKucha

- A PechaKucha consists of 20 slides timed to change every 20 seconds, so each presentation lasts 6 minutes and 40 seconds. Each presenter in PechaKucha session will be assigned a 10 minute slot to allow for a question to be posed. We anticipate that PechaKuchas will consist of short introductions to new work, methodological innovations or insights from the field. Please follow this link to learn more. Participants are encouraged to offer PechaKuchas in addition to traditional papers. 


\section{Key Dates}

- Call for papers, seminars and PechaKucha opens - November 21, 2016. Please follow this link to submit and learn more.

- $\quad$ Call for papers, seminars and PechaKucha closes - January 31, 2017

- $\quad$ Confirmation of papers, seminars and PechaKucha accepted for the conference rolling through December and no later than February 10, 2017

- $\quad$ Registration opens - January 162017

- $\quad$ Early-bird registration closes - March 3, 2017

- $\quad$ Registration closes - June 2, 2017

- $\quad$ Deadline for submission of papers and outlines to website. - June 9, 2017 